\title{
Certification of Quality as a Forerunner of Environmental Sustainability Standards Adoption in the Olive Oil Production Industry
}

\author{
Rocio Carillo Labella ${ }^{1}$, Manuel Parras Rosa ${ }^{1}$ \\ Fatiha Fort ${ }^{2}$, Eva María Murgado Armenteros ${ }^{1}$
}

\begin{abstract}
Agriculture is one of the sectors which is considered to have the greatest impact on the environment. That is particularly true in the area of olive oil production where the concept of sustainability is gaining a major importance not only for administrations and organisations but also for consumers and olive oil producers. This sector has previously focused on the quality management certified by different standards (ISO 9001, ISO 22000, BRC, and IFS); however, these days some interest in environmental responsibility is being shown. This interest goes beyond what is being enforced by the regulations and we can see this by the implementation of environmental standards such as the ISO 14001 within these companies. In this paper, through the analysis of the adoption processes of the ISO 14001 standard by both cooperatives and non-cooperative companies, we can determine their level of involvement in the environmental sustainability of olive oil production in the province of Jaén (Spain), where $20 \%$ of the world's production is located. To that effect, we have first studied how many of the 330 companies analysed have adopted the ISO 14001 standard and secondly, qualitative research has been carried out with in-depth interviews involving some of the previously mentioned companies. Results obtained reveal that previous experience of the certification processes ease the adoption of new environmental certifications in such a way that companies which have adopted the ISO 14001 or have stated their intention of doing so possess a high degree of adherence to the ISO 9001 standard. At the same time, they consider that the adoption of that standard makes them more competitive in foreign markets.
\end{abstract}

Keywords: environmental sustainability, ISO 14001, ISO 9001, competitiveness, foreign trade, olive oil

\section{Introduction}

After the globalisation and market opening, there has been a considerable increase in the adoption of international quality and environmental management standards as ISO 9001 and 14001, which quickly spread across many countries and are now the most widely accepted regulations for management systems. They are recognised by more than a million companies in over 170 countries within many different business areas such as manufacturing, services, chemicals, pharmaceuticals, and particularly in the agri-food sector.

Although both regulations offer strategic advantages to the organisations, we should point out that the goals they pursue are very different. ISO 9001 belongs to the ISO 9000 family, which incorporates different aspects of quality management and includes some of the best-known standards within the ISO. These standards provide guidance and also serve as tools for the companies which both pursue continuous quality improvements and want to ensure that their products and services consistently meet the requirements of customers.

\footnotetext{
${ }^{1}$ Professor of marketing at the University of Jaén (Spain),

2Professor in Montpellier SupAgro (France)
} 
Furthermore, ISO 9000 offers advantages from an organisational perspective such as encouraging and improving relationships with suppliers and associates which subsequently enhances trust among stakeholders in respect of coherence, effectiveness and efficiency. With regard to customers, where the focus on quality management is greatest, the ISO standard tries not only to fulfil their demands but also to exceed their expectations. It provides an opportunity to create added value and increases the level of satisfaction, loyalty, reputation, sales and market share.

The ISO standard allows management to monitor both processes and results, as well as providing the opportunity to evaluate risk and to introduce appropriate measures in the allocation of suitable and sufficient human resources. Moreover, regarding the employees, it enables them to refine and to better understand their goals, producing higher participation, greater creativity and significantly better collaboration with the organisation (ISO 900:2015).

Specifically, ISO 9001:2015 is a regulation that, on the one hand, focuses on the quality management system, which allows the company to demonstrate its capacity to supply products and services, thus meeting both the legal and regulatory requirements of customers. On the other hand, it helps to increase customer satisfaction through the effective implementation of the management system, including processes to improve and guarantee conformity with the customers' requirements. A combination of actions that allows the attraction of customers, the development of new products and services, the reduction of waste and the improvement of productivity (ISO 9001:2015).

The objective of ISO 14001 is to protect the environment through the reduction and prevention of environmental impacts, to offer support in fulfilling environmental legal requirements and to improve environmental performance. In addition to these, ISO 14001 will assist the company to attain financial and operational benefits after the implementation of eco-friendly alternatives and to develop better communication channels between interested parties in the whole production process. The adoption of both regulations is a strategic decision that may help the organisation's global performance providing a solid basis for both organisational and environmental development initiatives.

Nowadays and since the concept of sustainability appeared in 1987, there are more and more companies backing sustainability in its three dimensions, i.e. social, economic and environmental, the environmental aspect having the greatest influence on the company's marketing actions (Chabowski, Mena and Gonzalez-Padron, 2011). Environmental initiatives can be considered crucial for the organisations' future competitiveness (Menon and Menon, 1997; Nidumolu, Prahalad and Rangaswami, 2009; Sharma, Iyer, Mehrotra and Krishnan, 2010). Furthermore, they can contribute to a higher yield and benefit from greater competitivity and innovation (Klassen and Whybark, 1999; Majumdar and Marcus, 2001; Kassinis and Vafeas, 2006). Also it should not be forgotten that green strategies report long-term and vague benefits (Pedersen, Neergaard, Pedersen and Gwozdz, 2013).

Both regulations have gained importance in the agri-food sector and especially in the olive oil production sector where we can observe an emerging growth of green behaviour and its certification validation through the implementation of ISO 14001 (Carrillo, Parras and Albarracín, 2016). Therefore, we have resorted to primary 
information sources by the study of 330 olive oil production companies in the province of Jaen with the intention of identifying which have adopted the principle of voluntarism towards these two ISO regulations.

It has been found that the certification of quality ISO 9001 is more extensive than the environmental standard ISO 14001, and all those companies having ISO 14001 had previously adopted ISO 9001 (Fig. 1).

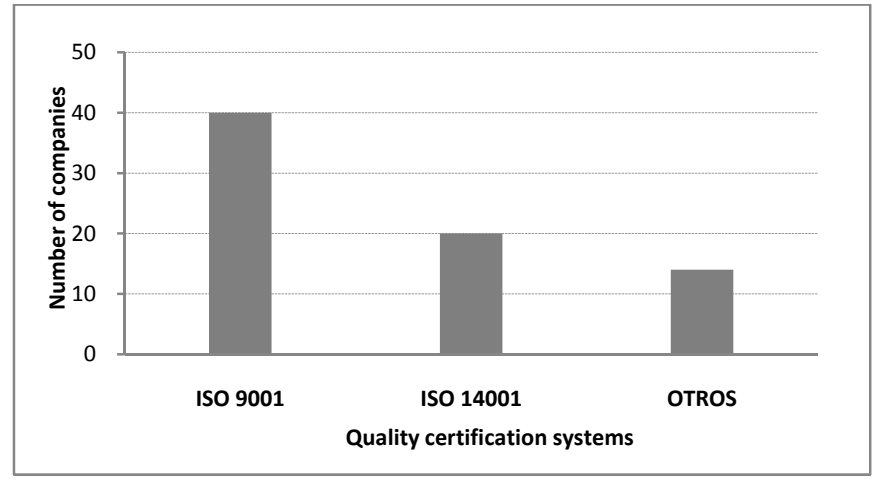

Figure 1: Quality certification systems present in olive mills in Jaén

Source: the authors

This behaviour, added to the fact that environmental sustainability has become more important, gives us two subjects to study: 1) To identify motivations, barriers and benefits in the adoption of ISO 9001; 2) To analyse ISO 9001 as a key element in the adoption of eco-friendly conducts and their certification through ISO 14001.

This document is divided into five parts: In the first, we propose a revision of the incentives, barriers and benefits of both ISO regulations; in the second, we establish the objectives and research methodology; in the third, we expose the results of the analysis; in the fourth, we summarise the main conclusions; and in the fifth and final part, we highlight the limitations of the research and future lines of investigation.

\section{Quality and Environmental Management Systems (ISO 9001, ISO 14001)}

There is a significant amount of research about the incentives, barriers and benefits that ISO 9001 \& 14001 quality systems provide for organisations. Regarding ISO 9001 and since its introduction in 1987 by the International Organization for Standardization (ISO), the major contribution in organisational competitiveness that it has introduced is still one of its main features (Sampaio, Saraiva and Guimaraes, 2009). In their revision on incentives, barriers and benefits of the implementation of the ISO 9001 in the article "Quality management systems: A study in companies of southern Spain and northern Morocco", Carmona-Calvo, Suárez, Calvo-Mora and PeriáñezCristóbal (2016) present the literature which classifies both internal and external incentives.

From an internal perspective, we need to point out the inside conviction of quality improvement beyond market demands, error and costs reduction, communication, 
productivity and key processes improvement, pursuit of operational efficacy and efficiency, employers' motivation and profitability (Sampaio et al., 2009; Carmona-Calvo et al., 2016).

Among external incentives are the improvement of the image and reputation of the company, easement of customers and governmental pressure and the introduction of the company into new markets (Sampaio et al., 2009; Kim, Kumar and Kumar, 2011; Carmona-Calvo et al., 2016) and marketing reasons.

Certification can be considered a formal indication of a Quality Assurance System (QAS) that might be used as proof that the company is responsible and is following international common marketing rules. This can lead to marketing benefits such as business expansion, new customers, new orders and penetration into new markets (Wu and Jang, 2014).

With regard to implementation barriers, we must consider the excess of bureaucracy and the time constraints of employees, the lack of knowledge that the programme exists and also a lack of involvement of executive managers (Sampaio et al., 2009; Al-Najjar, 2011). Cost-benefit relation and, to a lesser extent, employees' training and participation also have an effect (Carmona-Calvo et al., 2016). In addition, we must mention audit-related factors which can also be barriers as the organisation is committed to self-maintenance and pursues fast marketing goals (Zeng, Tian and Tam, 2007; Magd and Nabulsi, 2012).

As far as the benefits are concerned, we can identify internal and external advantages (Tarí, Molina-Azorín and Heras, 2012). Internal benefits would be those such as satisfaction, safety and security at work and cost-savings. As for the external benefits we find customer satisfaction, increase market share and improvement of financial, operative and sales results (Casadesús y Karapetrovic, 2005), implementation and consecution of more standardized processes at work, and improvement of the quality of the products and services (Carmona-Calvo et al., 2016).

ISO 14001 regulation constitutes a management tool that focuses on environmental consequences. This allows companies to set environment-friendly practices which from an operative perspective could result in a substantial business element, contributing to better monitoring and control of waste and reduction of noise resulting in a saving of energy and resources, thus improving both the company's reputation and relationship between interested parties (Potoski and Prakash, 2005), differentiating the products offered from competitors' and obtaining a better profitability (Da Silva y Texeira, 2008). ISO 14001 has generated a growing interest both among companies and in the scientific literature, creating two big fields of study, one focusing on the reasons for its adoption and the other on the financial aspects of that adoption (Ivanova, Gray and Sinha, 2014). Another aspect analysed has been the companies' behaviour regarding ISO 14001 and their marketing strategies, where it has been noted that the ISO is occasionally used as a marketing tool more than as a reason to modify manufacturing processes in order to improve the environment (Le, Vu, Hens and Van Heur, 2014).

ISO 14001 has been widely analysed regardless of the size of company, both in developed and emerging economies as well as in different sectors such as manufacturing, chemical, pharmaceutical, financial, the hotel sector, port refineries and to a lesser extent, in the agri-food sector. Literature reveals that the ISO tends to be more widely implemented in big companies than in SME, as bigger companies can deal with startup 
costs of the ISO certification more easily (Nishitani, 2009), and that agricultural companies possess a higher level of application than service sector companies (Singh, Jain and Sharma, 2015).

Among the main decisive variables in adopting the regulation, we find that some companies have an organisational nature and also a desire to pursue a competitive advantage (Pereira-Moliner, Font and Molina-Azorín, 2015). Other variables include employees and managers pressure (Alt, Díez-de-Castro and Lloréns-Montes, 2015), institutional variables such as environmental normative pressure (Zeng, Tam, Tam and Deng, 2005), sales variables like customer and distributor pressure and the access to new markets (McGuire, 2014). The desire to reduce costs constitutes a financial variable (Fruxell, Lo and Chung, 2004; He, Liu, Ly and Cao, 2015). Marketing variables include also image and reputation, brand differentiation (Singh et al., 2015), as well as sales and market share growth (Fruxell et al., 2004). ISO 14001 can be a visible and relevant instrument in the value chain (Ferrón, Darnall and Aragón-Correa, 2017).

In respect of the agri-food sector, research points out that it is heading towards product certification (Brotons and Sansalvador, 2016) particularly in the olive-oil sector (ParrasLópez, Hinojosa-Rodríguez, Carmona-Torres and Sayadi, 2016).

Among the reasons that incentivise agri-food companies to invest in ISO 9001 systems we find internal organisation issues and pressure from customers and markets, being the major factors discouraging the introduction of these systems (Maza and Ramirez, 2005; Carmona-Calvo et al., 2016; Parra-López et al., 2016).

On its behalf, the olive oil manufacturing sector has increased the application of ecofriendly practises regarding ISO 14001, despite being more worried about quality and its certification (ISO 9001). However, there is also an increasing concern about that regulation, as new environmental regulations must be followed (legal pressure).

ISO 14001 guarantees that all those regulations are being followed, conveying peace of mind to customers when purchasing those products and instilling a better image to consumers and society which leads to a better reputation especially in foreign markets where consumers demand higher quality and eco-friendly products.

ISO 14001 also eases business talks and commercialisation of products with big exporters who are more a more demanding regarding environmental activities. Competitivity and differentiation as well as image and reputation improvement are some of the motivating factors that are expected to have an effect on sales and profitability.

On the one hand, costs and implementation investment and bureaucracy and ignorance of the regulation are detected as barriers but on the other, there can be benefits such as new markets, internal improvements and a higher profitability of the organisation (Carrillo and Parras, 2016).

In this sector, ISO 14001 has been adopted after ISO 9001 in a way that every company which possesses ISO 14001 had previously implemented ISO 9001. We see the same behaviour in many other international companies that have embraced ISO 14001 only after the implementation of ISO 9001, driven by demand and other interested parties like the government and customers (Prajojo, Tang and Lai, 2012).

This can let us see that quality management can have some impact on environmental management (Pereira Moliner, Claver-Cortés, Molina-Azorin and Tarí, 2012; Zhu, Sarkis and Lai, 2013); these authors came to the conclusion that quality systems can be 
considered as important precursors of environmental management and in addition, that they have an influence in the efficiency and maturity of environmental management (Lopes de Sousa, Chiappetta, Latan, Teixeira and Caldeira de Oliveira, 2015).

\section{Methodology and Objectives of the Research}

As previously revealed, quality standard ISO 9001 is more extensive than environmental standard ISO 14001 in the olive oil manufacturing sector, and companies adopting the latter are already in possession of ISO 9001. Conversely, previous research shows the influence that quality management can have on the company's environmental management (Pereira Moliner et al., 2012; Zhu et al., 2013) and that quality systems can be considered as important precursors of environmental management. In addition, quality systems have an influence in the efficiency and maturity of environmental management (Lopes de Sousa et al., 2015).

Taking that into consideration, we set the following objectives in this research:

1) To identify motivations, barriers and benefits of the adoption of ISO 9001.

2) To analyse the role of ISO 9001 in the adoption of pro-environmental behaviours and their certification through ISO 14001, and the way the ISO supports organisational sustainability.

To achieve both objectives, qualitative research has been carried out using semistructured interviews with executive directors and managers of quality departments from olive oil manufacturers in the Jaén area. The sample consists of 20 organisations of varying size and legal form (cooperatives and non-cooperative companies) which possess an export intention.

\section{Main Results}

Regarding our first objective, results show that the main incentives to implement the ISO regulation mainly come from organisational and market factors.

From the organisational point of view, companies state the need to register and systematise quality systems applied in both the field and olive mills, therefore creating the department of quality which specialises in the pursuit of quality, food safety and environmental preservation indicating a positive direction in the tasks and performance of employers.

Executive managers express the importance of audits and external evaluation and the advice provided on their behalf in the continuous improvement of the company's actions seeking customer satisfaction and competitiveness.

"...yes, of course, so we can evaluate ourselves and see if things are being done the right way..."

Other incentives involve market rationale: the pursuance of higher customer satisfaction and distribution channel requirements, especially in exports.

"...it is essential to have a framework to outline where to implement quality protocols and also to have external evaluations, as more and more customers are insisting on those quality certifications, especially bypermarkets..."

Another reason is brand reputation and differentiation in demanding markets as well as the need for profits, maybe not straight away but through sales actions. The regulations 
bring differentiation to the company, which achieves a better acceptance, higher incomes and a greater market share.

We also find barriers ranging from the initial bureaucracy and the ignorance of employees to the regulations, to difficulties in adapting to the new protocols and methodology as well as audit periods and paperwork that can take time the company might not have.

As for the expected benefits of the regulation, we mainly find a greater satisfaction of managers, employees and customers as well as an improvement in the relationship with the distribution channel, especially with exportations. In the olive oil sector, many of the intermediaries require the company to possess the regulation to start any negotiation.

Regarding our second objective, research shows a positive relationship between the implementation of ISO 9011 and ISO 14001, as the former allows us to internalise the processes and specifies how things should be done in the organisation.

\section{Conclusions}

Globally we are seeing how the agri-food sector, and inside it olive-oil producers, are expected to meet consumers' and importers' requirements. Consumers are more and more aware of the quality on each of the links of the value chain.

Under such a scenario, olive oil producers are encouraging the development of the implementation of ISO 9001, triggered by internal organisational factors such as the internalisation of new processes and ways of how employees must carry out their tasks in addition to other aspects which lead to a greater satisfaction and motivation while performing those tasks.

Other motivational factors are the pursuance of competitivity, differentiation and to achieve customer satisfaction beyond their expectations through the continuous improvement of quality and distribution channels especially in the access to new markets. More and more, the sector is required to export production surpluses and it is thus essential to follow what customers and intermediaries require.

From a commercial point of view there are different motivations like achieving differentiation as well as a better image and reputation. From a financial perspective, the company looks for revenue, either straightaway or indirectly, through sales actions and the access to new markets which increases sales and market share.

As Tarí et al. (2012) point out, both regulations have similar benefits. Implementation of both ISO 9001 and ISO 14001 is motivated by several factors which include organisational, market, financial and institutional elements as well as competitivity, sales and market share, customers and distributors, reputation and brand image, product differentiation and revenue. However, the two ISOs have initially different goals: while ISO 9001 focuses on quality, ISO 14001 seeks environment improvement. This can make us think that both regulations are complementary, as seen in the olive oil sector where organisations who have implemented ISO 14001 had previously implemented ISO 9001. This can also be a precursor to better environmental behaviour which can lead to organisational sustainability.

With regard to our second objective, Quality Assurance Systems consider internal factors as values, culture, knowledge and performance and at the same time the external factors 
are defined as legal setting, culture and technology, competitiveness, markets and economics. They all let the company plan, design, produce, deliver and provide support for the products thus meeting the needs and expectations of customers (ISO 9000:2015). This second goal also allows the inclusion of improvements in product and service development and new modified processes, easing the insertion of eco-friendly procedures which are highly valued by customers. This allows companies to try to highlight their environmental sustainability from a commercial standpoint. All in all, we can conclude that there is a positive relationship between the implementation of both rules and that ISO 9001 can act as a good precursor for ISO 14001, contributing to its implementation and thus making organisations become sensitive about environment care.

\section{Limitations and Future Lines of Research}

One of the limitations we faced was as a result of only being able to interview 20 companies out of 330 , so it would be advantageous to undertake further research to clarify one of the unanswered questions which is the relationship between ISO 9001 implementation and profitability.

Another interesting development in the olive oil industry is that another certification, the ISO 22000, is becoming popular, focusing on food safety. This leaves the door open for future analysis of the relationship between the three regulations (ISO 9001, ISO 14001 and ISO 22000) and how the adoption of one ISO may affect the subsequent implementation of the others and their contribution to the company's income.

\section{References}

Al-Najjar, S.M. (2011): "ISO 9001 implementation barriers and misconceptions: an empirical study", International Journal of business Administration, Vol. 2, n 3, pp 118-131.

Alt, E. Díez-de-Castro, E.P. Lloréns-Montes, F.J. (2015): "Linking Employee Stakeholders to environmental performance: the role of proactive environmental strategies and shared vision", Journal Business Ethics, Vol. 128, pp 167-181.

Brotons, J.M. Sansalvador, M.E. (2016): "The value of ISO 9001 certification in the Spanish small and medium enterprises belonging to the agriculture sector: the impact of the economic crisis", Iteainformacion Tecnica Economica Agrarian, Vol. 112 n¹, pp 72-87.

Carmona-Calvo, M.A. Suárez, E.M. Calvo-Mora, A. Periáñez-Cristóbal, R. (2016): “Quality management systems: A study in companies of southern Spain and northern Morocco", European Research on Management and Business Economics, Vol. $22 \mathrm{n}^{\circ}$ 1, pp 8-16.

Carrillo, R. Parras, M. Albarracín, A.L. (2016): "Motivaciones y barreras para la adopción de la ISO 14001 en el sector oleícola: una aproximación a través del caso Jiennense", XVII Encuentro AECA, http://www.xviiencuentroaeca.ipb.pt/docs/artigos/49c.pdf.

Casadesús, M. Karapetrovic, S. (2005): “The erosion of ISO 9001 benefits: A temporary study International", Journal of Quality \& Reliability Management, Vol. 22 n², pp 120-136.

Chabowski, B. Mena, J. Gonzalez-Padrón, T. (2011): “The structure of sustainability research in marketing, 1958-2008: a basis for future research opportunities", Journal of the Academy Marketing of Science, Vol. 39, pp 55-70.

Da Silva, R.V. Teixeira, N. (2008): “Environmental Business strategy: The Portuguese case", Business Strategy and the Environmental, Vol. 17, pp 208-218.

Ferrón, V. Darnall, N. Aragón-Correa, J.A. 201: "Stakeholders influences on the design of firms' environmental practices”, Journal of Cleaner Production, Vol. 142, pp 3370-3381. 
Fryxell, G.E. Lo, C. Chung, S. (2004): "Influence of motivations for seeking ISO 14001 certification on perceptions of EMS effectiveness in China", Environmental Management, Vol. 33, nº 2, pp 239-251.

He, W. Liu, C. Lu, J. Cao, J. (2015): "Impacts of ISO adoption on firm performance: evidence from China", China Economic Review, Vol. 32, pp 43-56.

ISO (2015): ISO 9000 Quality Management. International Organization for Standardization (ISO Available at https://www.iso.org/standard/45481.html Acceded 15.12.2016.

ISO (2015): ISO 9001 Quality Management. International Organization for Standardization (ISO Available at https://www.iso.org/news/2015/09/Ref2002.html, Acceded 16.12.2016.

ISO (20015): ISO14001 Environmental Management. International Organization for Standardization (ISO Available at https://www.iso.org/standard/60857.html Acceded 12.12.2016.

Ivanova, A. Gray, J. Sinha, K. (2014): "Towards a unifying theory of management standard implementation: The case of ISO 9001/ISO 14001", International journal of operations and production management, Vol. $34, n^{\circ} 10$, pp 1260-1306.

Kassinis, G, Vafeas, N. (2006): "Stakeholder pressures and environmental performance", Academy of Management Journal, Vol. 49, 145-159.

Kim, D.Y. Kumar, V. Kumar, U. (2011): "A performance realization framework for implementing ISO 9000", International Journal of Quality Reliability Management, Vol. 28 n 4, pp 383-404.

Klassen, R.D. Whybark, D.C. (1999): "The impact of environmental technologies on manufacturing performance", Academy of management Journal, Vol. 42 nº, pp 599-614.

Le, X.Q. Vu, V. H. Hens, L. Van Heur, B. (2014): "Stakeholders perceptions and involvement in the implementation of EMS in ports in Vietnam and Cambodia", Journal of Cleaner Production, Vol. 64, pp 173-193.

Lopes de Sousa, A.B. Chiappetta, C.J. Latan, H. Teixeira, A. Caldeira de Oliveira, J.H. (2015): “Quality management, environmental management maturity, green supply chain practices and green performance of Brazilian companies with ISO 14001 certification: direct and indirect effects", Transportation Research Part E, Vol. 74, pp 139-151.

Magd, D. Nabulsi, F. (2012): "The effectiveness of ISO 9000 in an emerging market as a business process management tool: the case of the UAE", Procedia Economics and Finance, Vol. 3, pp 158-165.

Majumdar, S, Marcus, M. A. (2001): "Rules vs. discretion: the productivity consequences of flexible regulation", Academy of Management Journal, Vol. 44 nº 1, pp 170-179.

Martínez, L, Martínez, J. A. (2009): "Does ISO 9000 certification affect consumer perceptions of the service provider?", Managing Service Quality, Vol. 19 n 2, pp 140-161.

Maza, M. Ramirez, V. (2005): "Study of the Main Motivations and Discouraging Factors for the Implementation of ISO 9000 Standards in Spanish Agribusiness Sector", Journal of International Food and Agribusiness Marketing, Vol. $17 \mathrm{n}^{\circ}$ 2, pp 229-243.

McGuire, W. (2014): “The effect of ISO 14001 on environmental regulatory compliance in China”, Ecological Economics, Vol. 105, pp 254-264.

Menon, A. Menon, A. (1997): "Enviropreneurial marketing strategy: the emergence of corporate environmentalism as market strategy", Journal of Marketing, Vol. 61 n 1, pp 51-67.

Nidumolu, R. Prahalad, C.K. Rangaswami, M.R. (2009): "Why sustainability is now the key driver of innovation" Harvard Business Review, Vol. 87, pp 57-64.

Nishitani, K. (2009): "An empirical study of the initial adoption of ISO 14001 in Japanese manufacturing firms", Ecological Economics, Vol. 68, pp 669-679.

Parra-López, C. Hinojosa-Rodriguez, A. Carmona-Torres, C. Sayadi, S. (2016): "ISO 9001 implementation and associated manufacturing and marketing practices in the olive oil industry in southern Spain", Food Control, Vol. 62, pp 23-31.

Pedersen, E.R. Neergaard, P. Pedersen, J.T. Gwozdz, W. (2013): “Conformance and deviance: company responses to institutional pressures for corporate social responsibility reporting", Business Strategy and the Environment, Vol. $22 \mathrm{n}^{\circ}$ 6, pp 357-373.

Pereira-Moliner, J. Claver-Cortés, E. Molina-Azorín, J.F. Tarí, J.J. (2012): "Quality management, environmental management and firm performance: direct and mediating effects in the hotel industry", Journal of Cleaner Production, Vol. 37, pp 82-92.

Pereira-Moliner, J. Font, X. Molina-Azorin, J.F. Tarí, J.J. (2015): “The holy grail environmental management, competitive advantage and business performance in the Spanish hotel industry", International Journal of Contemporary Hospitality Management, Vol. 27 n 5, pp 714-738. 
Potoski, M. Prakash, A. (2005): “Covenants with weak swords: ISO 14001 and facilities' environmental performance", Journal of policy Analysis and Management, Vol. 24, pp 745-769.

Prajogo, D. Tang, A.K.Y. Lai, K. (2012): "Do firms get what they want from ISO 14001 adoption?: an Australian perspective", Journal of Cleaner Production, Vol. 33, pp 117-126.

Sampaio, P. Saraiva, P. Guimarães, A. (2009): "ISO 9001 certification research: Questions, answers and approaches", International Journal of Quality \& Reliability Management, Vol. 26 nº 1, pp 38-58.

Sharma, A. Iyer, G.R. Mehrotra, A. Krishnan, R. (2010): "Sustainability and business-to-business marketing: a framework and implications", Industrial Marketing Management, Vol. 39 n 2, pp 330-341.

Singh, N. Jain, S. Sharma, P. (2015): "Motivations for implementing environmental management practices in Indian industries", Ecological Economics, Vol. 109, pp 1-8.

Tarí, J.J. Molina-Azorín, J.F. Heras, I. (2012): "Benefits of the ISO 9001 and ISO 14001 standards: A literature review", Journal of Industrial Engineering and Management, Vol. 5 n 2, pp 297-322.

Wu, S. Jang, J. (2014): “The impact of ISO certification on consumers' purchase intention”, Total Quality Management \& Business Excellence, Vol. 25 n 3-4, pp 412-426.

Zeng, S.X. Tam, C.M. Tam, V. Deng, Z.M. (2005): “Towards implementation of ISO 14001 environmental management systems in selected industries in China", Journal of Cleaned Production, Vol. 13, pp 645656.

Zeng, S. X. Tian, P. Tam, C. M. (2007): "Overcoming barriers to sustainable implementation of the ISO 9001 system”, Managerial Auditing Journal, Vol. 22 n 22, pp 244-254.

Zhu, Q. Sarkis, J. Lai, K. (2013): "Institutional pressures, dynamic capabilities and environmental management systems: investigating ISO 9000 environmental management systems implementation linkage", Journal of Environmental Management, Vol. 114, pp 232-242. 